\title{
Design and Analysis of a Photonic Crystal Based Planar Antenna for THz Applications
}

\author{
Inzamam Ahmad $^{1}$, Sadiq Ullah ${ }^{1, *(\mathbb{D})}$, Shakir Ullah ${ }^{1} \mathbb{D}$, Usman Habib ${ }^{2} \mathbb{D}$, Sarosh Ahmad ${ }^{3}$, Adnan Ghaffar ${ }^{4}(\mathbb{D}$, \\ Mohammad Alibakhshikenari ${ }^{5, *(D)}$, Salahuddin Khan ${ }^{6, *(D)}$ and Ernesto Limiti ${ }^{5}$ (D)
}

check for

updates

Citation: Ahmad, I.; Ullah, S.; Ullah, S.; Habib, U.; Ahmad, S.; Ghaffar, A.; Alibakhshikenari, M.; Khan, S.; Limiti, E. Design and Analysis of a Photonic Crystal Based Planar Antenna for $\mathrm{THz}$ Applications. Electronics 2021, 10, 1941. https://doi.org/10.3390/ electronics10161941

Academic Editor: Giovanni Andrea Casula

Received: 2 July 2021

Accepted: 8 August 2021

Published: 11 August 2021

Publisher's Note: MDPI stays neutral with regard to jurisdictional claims in published maps and institutional affiliations.

Copyright: (c) 2021 by the authors. Licensee MDPI, Basel, Switzerland. This article is an open access article distributed under the terms and conditions of the Creative Commons Attribution (CC BY) license (https:// creativecommons.org/licenses/by/ $4.0 /)$.
1 Department of Telecommunication Engineering, University of Engineering and Technology, Mardan 23200, Pakistan; inziahmad950@gmail.com (I.A.); shakirhayat.eng@gmail.com (S.U.)

2 School of Computer Science and Electronic Engineering, Bangor University, Bangor LL57 2DG, UK; u.habib@bangor.ac.uk

3 Department of Electrical Engineering and Technology, Government College University Faisalabad (GCUF), Faisalabad 38000, Pakistan; saroshahmad@ieee.org

4 Department Electrical and Electronic Engineering, Auckland University of Technology, Auckland 1010, New Zealand; aghaffar@aut.ac.nz

5 Electronic Engineering Department, University of Rome “Tor Vergata”, Via Del Politecnico 1 , 00133 Rome, Italy; limiti@ing.uniroma2.it

6 College of Engineering, King Saud University, P.O. Box 800, Riyadh 11421, Saudi Arabia

* Correspondence: sadiqullah@uetmardan.edu.pk (S.U.); alibakhshikenari@ing.uniroma2.it (M.A.); drskhan@ksu.edu.sa (S.K.)

\begin{abstract}
Modern advancements in wearable smart devices and ultra-high-speed terahertz (THz) communication systems require low cost, low profile, and highly efficient antenna design with high directionality to address the propagation loss at the THz range. For this purpose, a novel shape, high gain antenna for $\mathrm{THz}$ frequency range applications is presented in this work. The proposed antenna is based on a photonic bandgap (PBG)-based crystal polyimide substrate which gives optimum performance in terms of gain $(9.45 \mathrm{~dB})$, directivity $(9.99 \mathrm{dBi})$, and highly satisfactory VSWR $(<1)$ at $0.63 \mathrm{THz}$. The performance of the antenna is studied on PBGs of different geometrical configurations and the results are compared with the antenna based on the homogeneous polyimide-based substrate. The effects of variations in the dimensions of the PBG unit cells are also studied to achieve a $-10 \mathrm{~dB}$ bandwidth of $28.97 \mathrm{GHz}(0.616$ to $0.64 \mathrm{THz})$.
\end{abstract}

Keywords: PBG; VSWR; THz; patch antenna

\section{Introduction}

The Terahertz (THz) frequency band $(0.1$ to $10 \mathrm{THz})$ has attained a lot of interest in the last decade due to the development of a cost-effective generation of $\mathrm{THz}$ signals [1] and its applications to fulfill the requirements of wideband and high data rate. Electromagnetic waves at THz have numerous applications for wireless communication [2], spectroscopy [3], remote sensing [4], medical diagnosis [5,6], high-speed communication [7], and radio astronomy [8]. Transmission in the $\mathrm{THz}$ frequency band can provide data rates of up to $100 \mathrm{~Gb} / \mathrm{s}$ per stream for future communication systems [9]. Especially for short-distance indoor or outdoor hotspots, wireless local area networks at terabits data rates (T-WLAN) [10] are potential candidates to provide wireless access, which can also be integrated with ultra-high-capacity optical fiber links [11] for Fixed Wireless Access (FWA). To support low cost and reliable transmission of $\mathrm{THz}$ signals, several design considerations are required for the transmission antenna such as low cost, compact size, large bandwidth, and high gain. Photoconductive materials making use of photo mixing radiators is considered the most general technique for $\mathrm{THz}$ transmission, but the low gain and phase noise (induced due to the line width of the remote laser source) is a major bottleneck. Directivity is an essential requirement to compensate for high free-space path loss at the THz range. As an alternative, 
microstrip patch antennas can make use of the high frequency of $\mathrm{THz}$ operation to provide a low-profile design, but their performance suffers due to the surface waves, resulting in low gain and low bandwidth [12]. Although the low bandwidth is an inherent feature of the microstrip antennas due to its resonant nature, high directivity with large bandwidth can be achieved using the photonic crystal (PC) technique for a robust and effective transmission design [13]. In PC-based design, photonic bandgap (PBG) structures are integrated into microstrip patch antennas to achieve better radiation properties. The PBG-based substrates can be used to overcome the limitation of surface waves [13] in planar microstrip antennas. This is achieved by embedding photonic crystals in the dielectric substrate. In this way, the PBG structure results in an improvement in gain, directivity, bandwidth, and radiation pattern by providing high attenuation for an undesired band of frequencies and resistance against the surface waves travelling within the substrate. Several variants of PBG structure such as circular PBG [14,15], triangular structure [16], meta-material structure [17,18], and surrounded structures [19] have been reported in recent literature. In addition, defected ground structure (DGS) [20] is another prominent method to achieve band-stop features and bandwidth enhancement.

This paper presents a novel design of a PBG substrate-based THz microstrip patch antenna; its performance was benchmarked with the recently reported $\mathrm{THz}$ patch antennas mounted on the homogeneous substrate. Different design parameters such as substrate height, patch shape, and radius of the patch were parameterized and optimized to achieve the best radiation performance. The paper is organized as follows: Section 2 presents the design of the proposed antenna. Following that, Section 3 presents the simulation results and related analysis. Finally, the conclusion of this article is given in Section 4.

\section{Proposed Antenna Structure}

This section covers the design details of the convention and proposed PBG-based antenna, intended for applications in the $\mathrm{THz}$ frequency band. Polyimide was used as a substrate material, having a loss tangent of 0.0025 and a dielectric constant of 3.5. The overall volume of the antenna was $700 \times 660 \times 192 \mu \mathrm{m}^{3}$. Furthermore, the design details of the presented $\mathrm{THz}$ antenna based on three different types of PBG substrate are also discussed. From now onwards, the following naming nomenclature will be used to differentiate between the different variants of the antenna that are discussed in this manuscript:

Type-A: THz antenna backed by a homogeneous substrate, shown in Figure 1a.

Type-B: THz antenna backed by PBG substrate with rectangular shape metallic insertions as shown in Figure 1b.

Type-C: THz antenna backed by PBG substrate with triangular shape metallic insertions, shown in Figure 1c.

Type-D: THz antenna backed by PBG substrate with circular shape metallic insertions, shown in Figure 1d.

The structural parameters of the four types of antennas are listed in Table 1. The Type-A antenna in Figure $1 \mathrm{a}$ is based on a homogenous substrate and is used as a reference antenna to evaluate the performance of the other antennas. Type- $\mathrm{B}$, shown in Figure $1 \mathrm{~b}$, is a THz antenna backed by PBG substrate with rectangular shape metallic insertions sized $25 \times 20 \mathrm{um}$ and separated by $95 \mathrm{um}$. Figure 1c is a Type-C THz antenna backed by PBG substrate with equilateral triangular shape metallic insertions with side length " $W_{t}$ " and separated by 95 um. Type-D, shown in Figure 1d, is a THz antenna backed by PBG substrate with circular shape metallic insertions with radius " $r$ " and separated by 95 um. Figure 1e shows the inner view of the substrate layer after insertion of the array of PBG unit cells. Later, it will be shown from the results that the Type-D provides the optimum performance compared to other designs; the dimensions of the antenna were obtained using well-known microstrip antenna theory [20] for the given frequency $\left(f_{r}\right)$ in hertz $(\mathrm{Hz})$, a substrate of dielectric constant $\left(\varepsilon_{r}\right)$, and height $\left(h_{s}\right)$ in units of centimeters. The effective radius of the 
antenna $\left(R_{c}\right)$ was obtained from the actual circular patch radius $(a)$ using the following equations [21]:

$$
a=\frac{F}{\left\{1+\frac{2 h_{s}}{\pi \varepsilon_{r} F}+\left[\ln \left(\frac{\pi F}{2 h_{s}}\right)+1.7726\right]\right\}^{1 / 2}}
$$

where $F$ is $8.791 \times 10^{9} / f_{r} \sqrt{\varepsilon_{r}}$. The effective radius of the antenna can be expressed as

$$
R c=a \sqrt{1+\frac{2 h}{\pi a}\left(\ln \left[\frac{a}{2 h}\right]+1.7726\right)} a
$$

where $f_{r}$ denotes the operating frequency in $\mathrm{Hz}, \varepsilon_{r}$ is the relative dielectric constant, and $\varepsilon_{\text {reff }}$ is the effective dielectric constant. Computation of width $\left(W_{f}\right)$ of the feed line is based on the input impedance $\left(Z_{a}\right)$ of the antenna, given by:

$$
Z_{a}=\frac{11.96 \lambda_{0}}{W_{f}}
$$

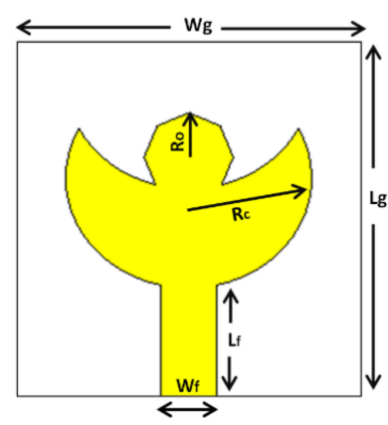

(a)

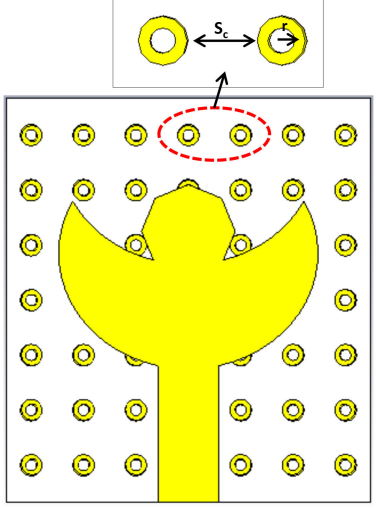

(d)

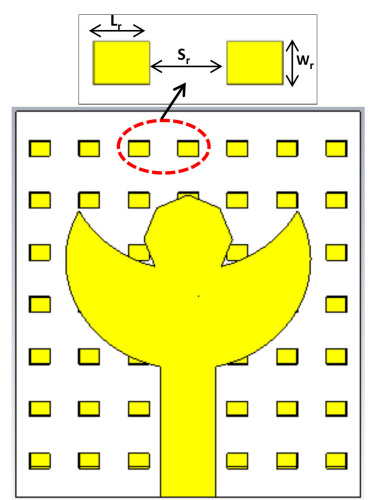

(b)

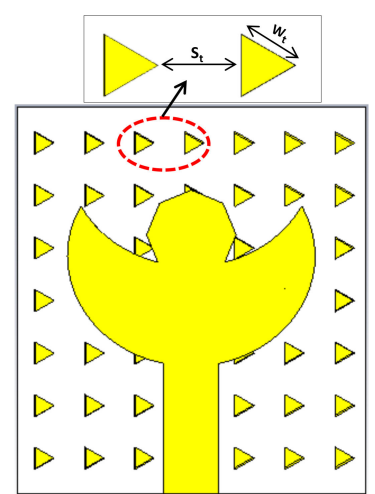

(c)

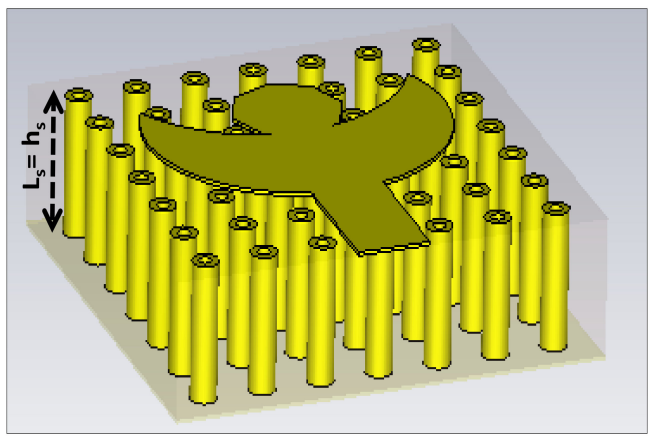

(e)

Figure 1. Different variants of the Proposed THz antenna (a) Type-A antenna (b) Type-B antenna (c) Type-C antenna (d) Type-D antenna (e) inner view of PBG unit cells of Type-D antenna Design.

Table 1. Design Parameters of the THz antennas.

\begin{tabular}{cccccc}
\hline Parameter & Value $(\boldsymbol{\mu m})$ & Parameter & Value $(\boldsymbol{\mu m})$ & Parameter & Value $(\boldsymbol{\mu m})$ \\
\hline$L_{g}$ & 700 & $R_{c}$ & 100 & $W_{r}$ & 25 \\
$W_{g}$ & 660 & $R_{h}$ & 75 & $S_{r}$ & 95 \\
$L_{f}$ & 240 & $S_{c}$ & 95 & $L_{r}$ & 20 \\
$W_{f}$ & 105 & $R$ & 16 & $S_{t}$ & 95 \\
$W_{t}$ & 85 & $R_{0}$ & 80 & $* * *$ & $* * *$ \\
\hline
\end{tabular}


The input impedance $\left(Z_{a}\right)$ was matched with the standard $50 \Omega$ impedance through a feeding line of length, $L_{f}$. The characteristic impedance of the feed line was $Z_{0}=50 \times Z_{a}$. The width of the feed line was obtained using:

$$
\begin{gathered}
W_{f}=\frac{7.475 h_{s}}{e^{x}}-1.25 t \\
x=\frac{Z_{0} \sqrt{\varepsilon_{r}+1}}{87}
\end{gathered}
$$

where $h_{s}$ and $t$ are the height of substrate and thickness of the patch, respectively.

The development of the design was performed in steps shown in Figure 2, which produced a different set of return loss characteristics as demonstrated in Figure 3. The value of $R_{0}$ was optimized to $80 \mu \mathrm{m}$ to achieve lowest return loss at the resonating frequency. Changes were made for improvement in antenna performance in terms of driving point impedance bandwidth and the return loss. Figure 3 depicts that step 1 was designed by designing a circular patch that gave a resonance frequency of $0.62 \mathrm{THz}$. In step 2, the circular patch was reduced to half-moon by subtracting half of the circle from the top, with an operating frequency of slightly higher than $0.63 \mathrm{THz}$. An octagon was embedded at the top of the half-moon shape in order to achieve the final design with better results in step 3 , having the resonance frequency of $0.63 \mathrm{THz}$.

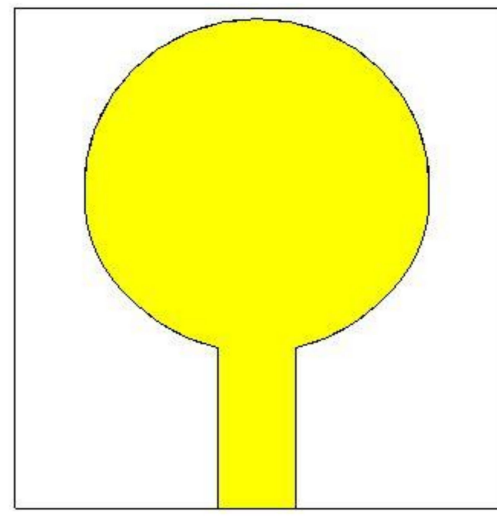

Step No 1

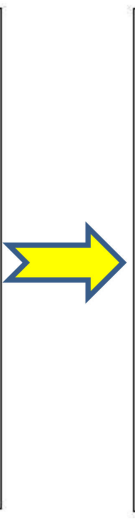

.

Figure 2. Design steps of Type-A antenna.

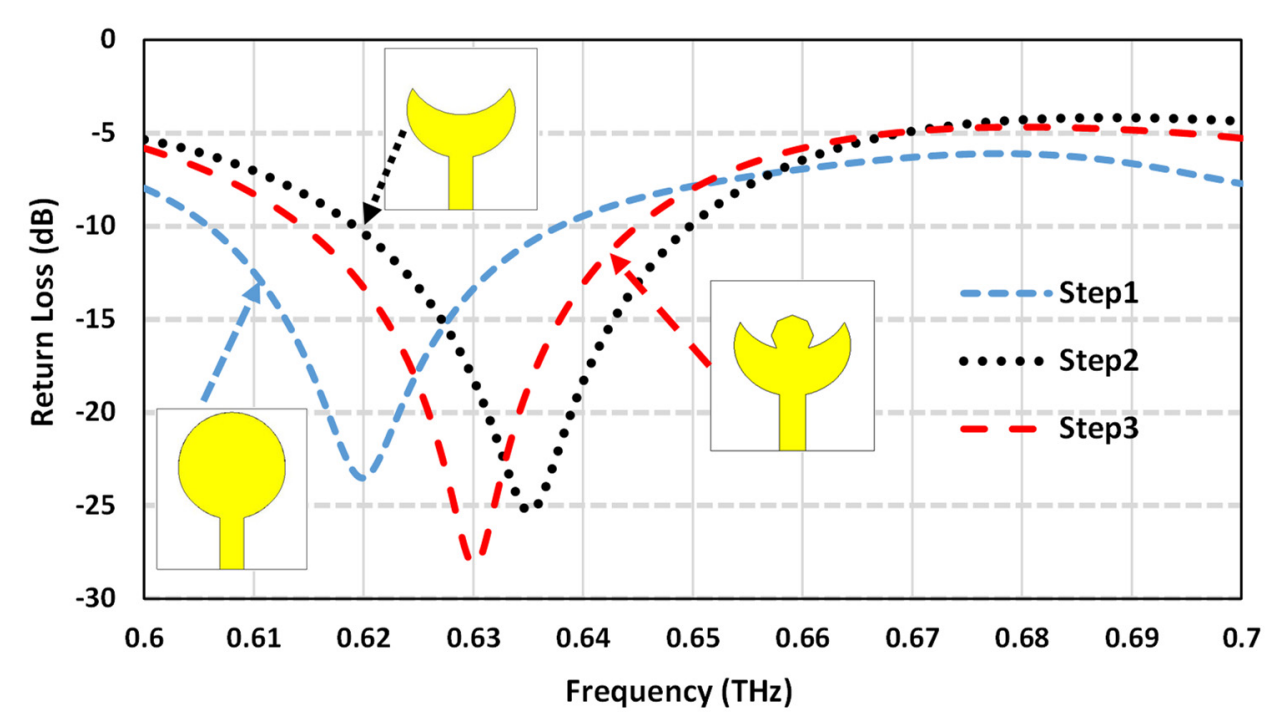

Figure 3. The return loss of design evaluation of Type-A antenna. 


\section{Simulation Results and Discussion}

The radiation characteristics of the proposed antennas were examined in the frequency range of 0.60 to $0.75 \mathrm{THz}$ using the Finite Integration Technique (FIT) available in CST Microwave Studio [22]. The performance of the antennas was analyzed in terms of return loss, gain, directivity, impedance bandwidth, VSWR, and radiation efficiency. Table 2 lists the simulation parameters for the performance analysis. It is evident from Figure 4 that Type-A and $\mathrm{D}$ antennas resonated at $0.63 \mathrm{THz}$, with $-10 \mathrm{~dB}$ bandwidths of $28.88 \mathrm{GHz}$ and $29.79 \mathrm{GHz}$, respectively. The resonant frequency of the Type-B antenna was slightly shifted upwards to $0.6233 \mathrm{THz}$, giving a $-10 \mathrm{~dB}$ bandwidth of $26.47 \mathrm{GHz}$. The Type-C antenna gave peak resonance at a lower frequency of $0.626 \mathrm{THz}$ with a $-10 \mathrm{~dB}$ bandwidth of $27.84 \mathrm{GHz}$. This comparison shows that the Type-D antenna provided wider bandwidth as compared to the other candidate antennas.

Table 2. Simulation parameters for the analysis of the proposed design.

\begin{tabular}{cccc}
\hline Type & Parameter & Unit & Value \\
\hline Simulation solver & Solver type & Ohm & Finite Integration technique \\
& Impedence & 50 & Hexahedral \\
& Mesh type for time Domain Solver & & 0.6 to 0.7 \\
Polyimide substrate & Frequency Range & $\mathrm{THz}$ & 3.5 \\
& Relative permitivity & Unitless & 1400 \\
& Density (rho) & $\mathrm{Kg} / \mathrm{m}^{3}$ & $\mathrm{GPa}$ \\
\hline
\end{tabular}

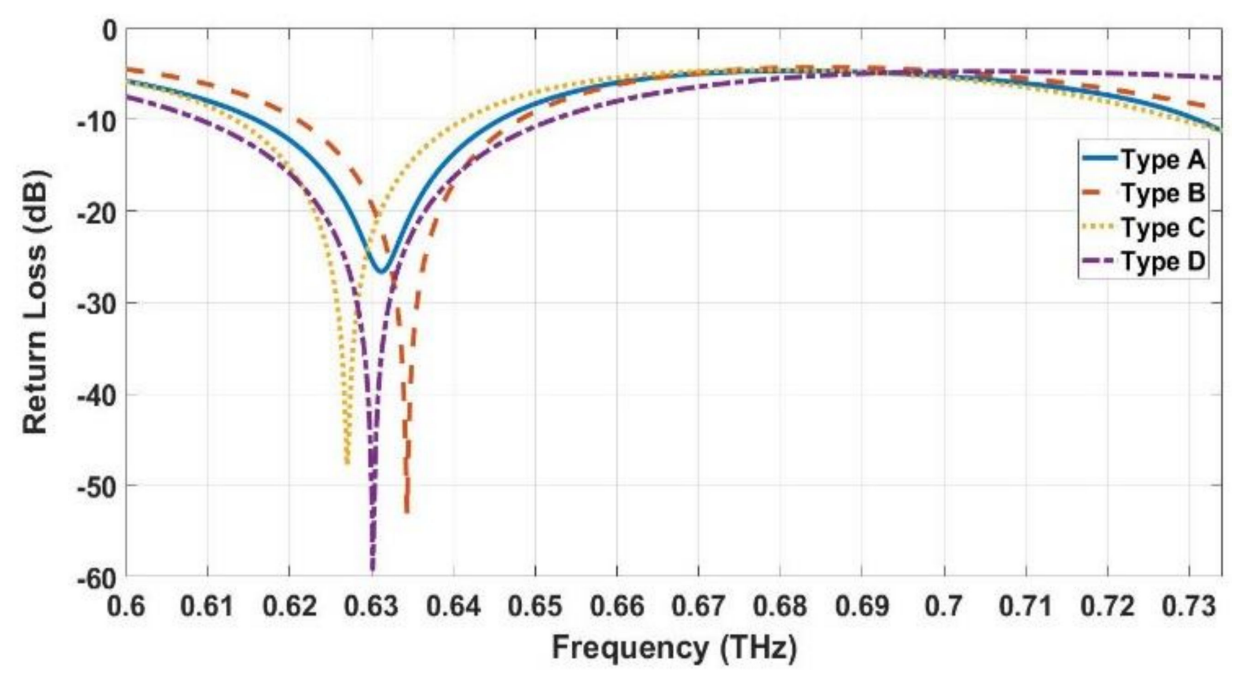

Figure 4. Comparison of return loss.

As shown in Figure 5, the VSWR of the four antennas was found to be less than 1.5 within the operational bandwidth of the antennas, which shows that the antennas were optimally matched to the feed line. It can be observed in Figure 6 that the Type-D antenna gave a better peak gain of $9.45 \mathrm{~dB}$ at the resonant frequency for wider bandwidth, as compared to the rest of the three $\mathrm{THz}$ antennas. The comparison of the radiation efficiency plots in Figure 7 shows that the PBG-based THz antennas are more efficient (87-90\%) as compared to the Type-A THz antenna, which was based on a homogeneous substrate with a radiation efficiency of $80 \%$. The better efficiency of the PBG-based antennas is due to the suppression of the surface waves by the PBG structure. 


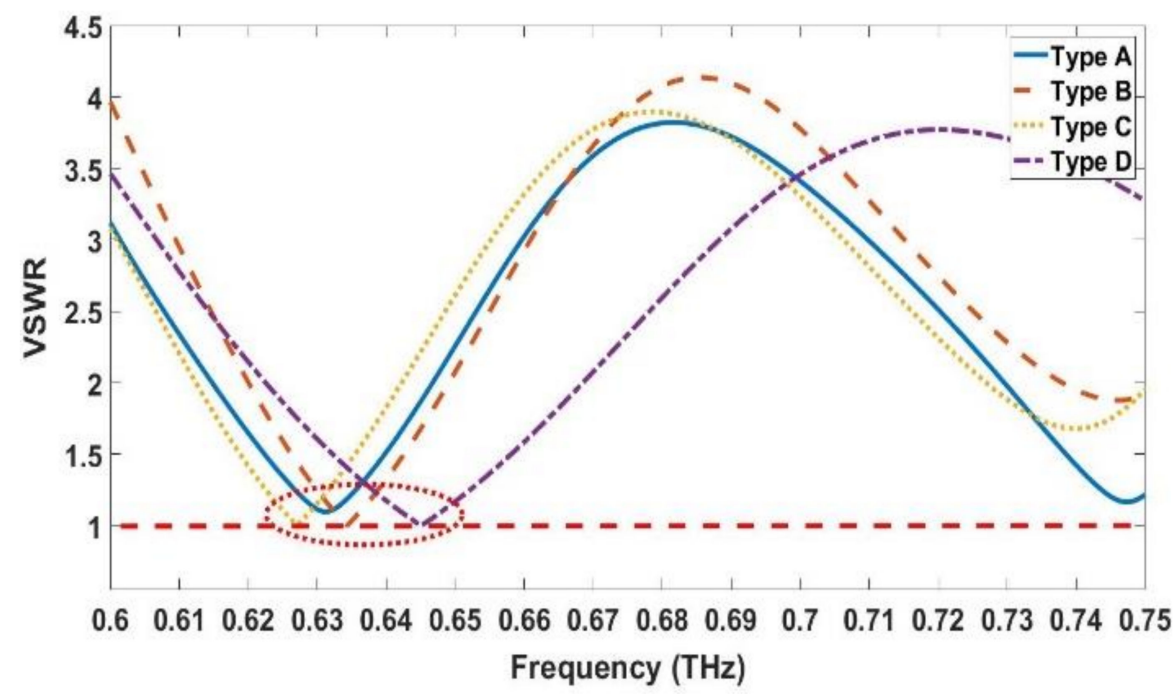

Figure 5. Comparison of VSWR versus operating frequency.

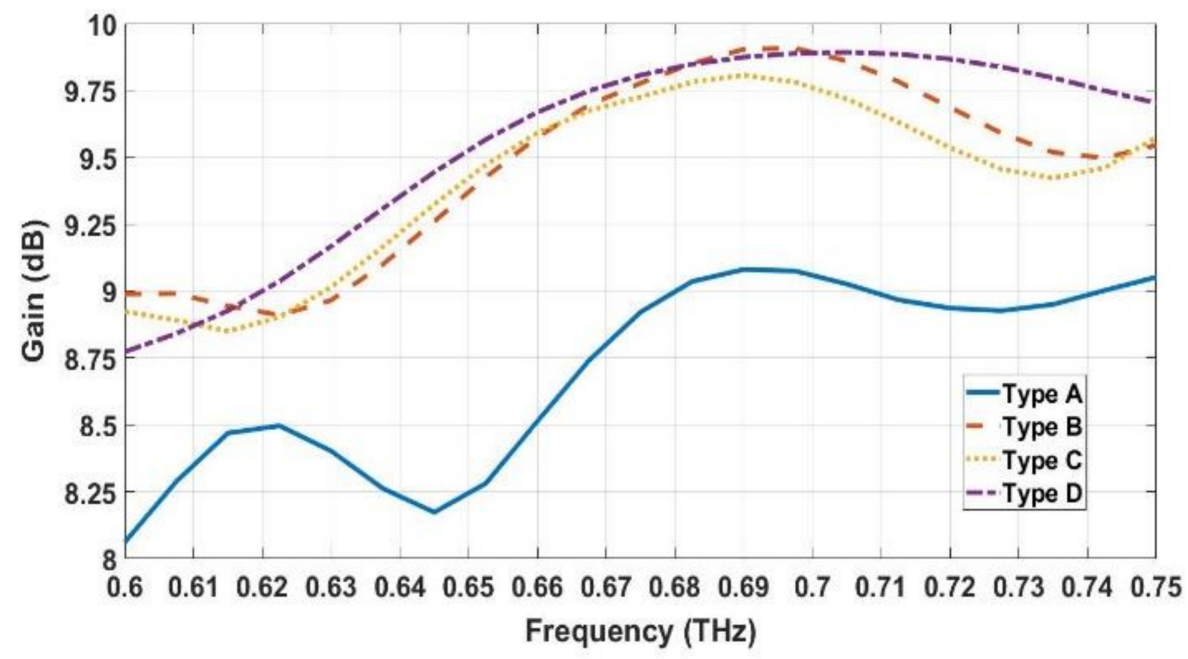

Figure 6. Comparison of peak gain for the four proposed types.

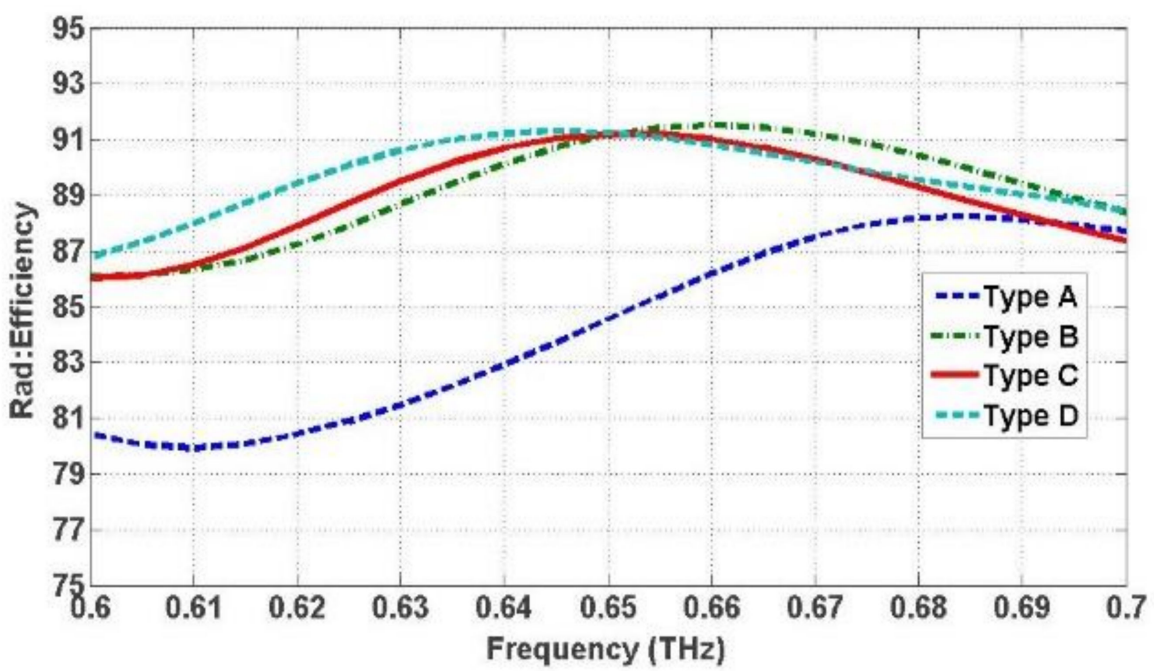

Figure 7. Comparison of radiation efficiency.

A simple equivalent circuit model for proposed compact size THz antenna was designed and then simulated in advanced designed system (ADS) software as shown in 
Figure 8, which provides an equivalent input impedance matching that of the antenna. The equivalent circuit consisted of one RLC (resistor-inductor-capacitor) parallel circuit connected in series with two resistors: an inductor and a capacitor. The use of resistors improves the reflection coefficient to less than $-10 \mathrm{~dB}$. The reflection coefficient of the $\mathrm{THz}$ antenna can be tuned by varying the values of the capacitors and inductors. Comparison of the reflection coefficients for the proposed antenna $S_{11}$ with that of the circuit model is presented in Figure 9, which shows good agreement between the two sets of results.

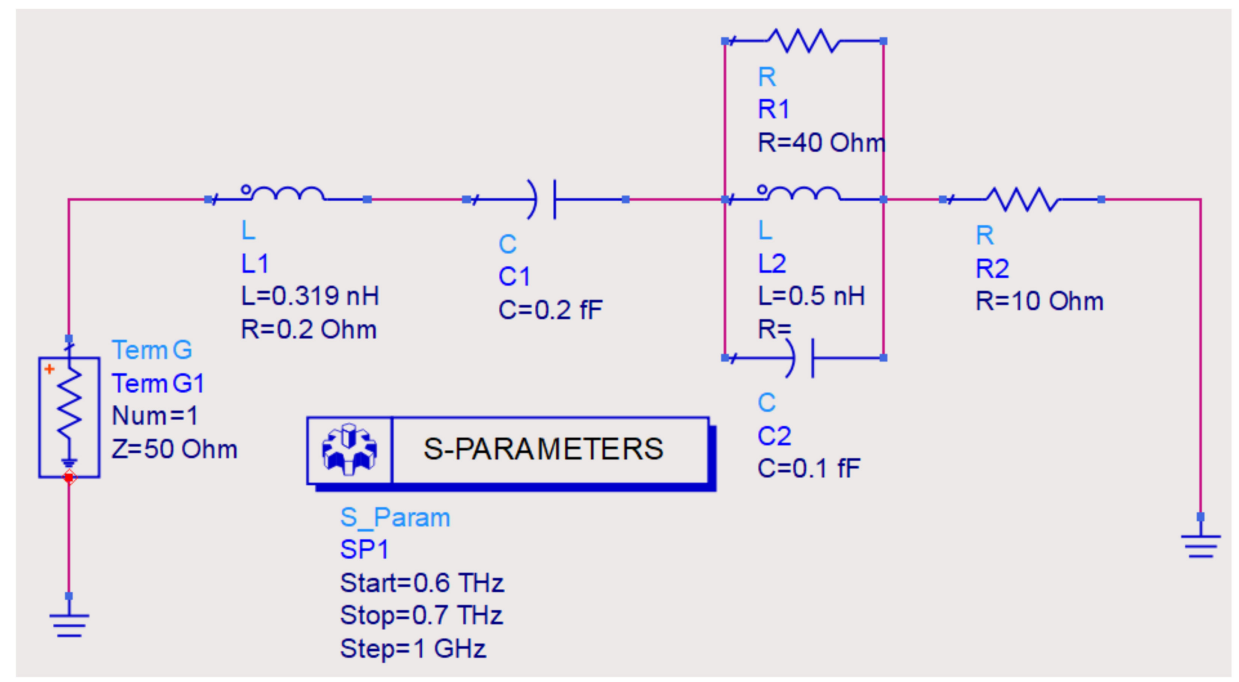

Figure 8. Equivalent circuit model for the proposed antenna design.

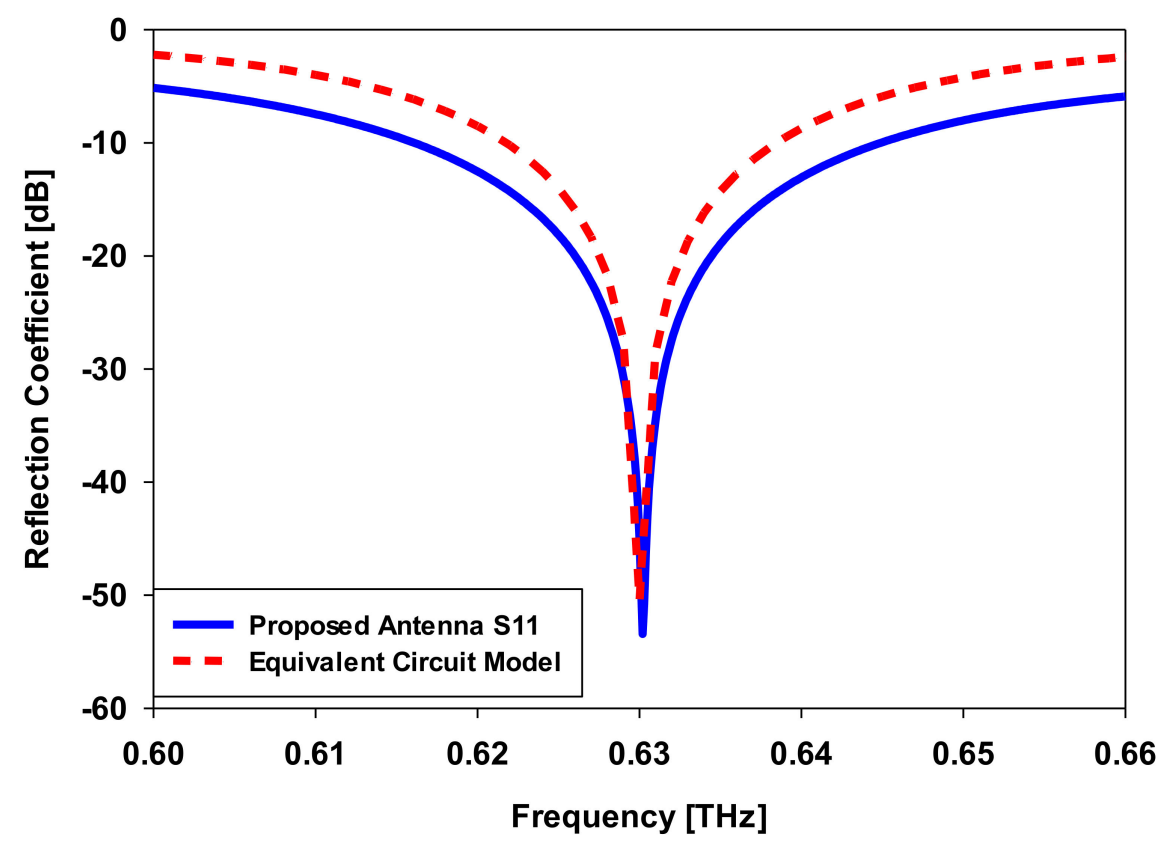

Figure 9. Comparison of reflection coefficient.

The three-dimensional radiation patterns of the $\mathrm{THz}$ antennas are illustrated in Figure 10, which shows that the Type-D antenna offered the highest gain $(9.45 \mathrm{~dB})$ at $0.63 \mathrm{THz}$, as compared to the rest of the antennas. The two-dimensional radiation pattern of the antennas in the two principal planes (E-plane and H-plane) is portrayed in Figure 11. The radiation pattern of the antennas was relatively broader in the H-plane as compared to the E-plane. The results show that the peak gain of the antennas occurred at $90^{\circ}$, with the highest half-power beamwidth of $105^{\circ}$ for the Type-D antenna. 

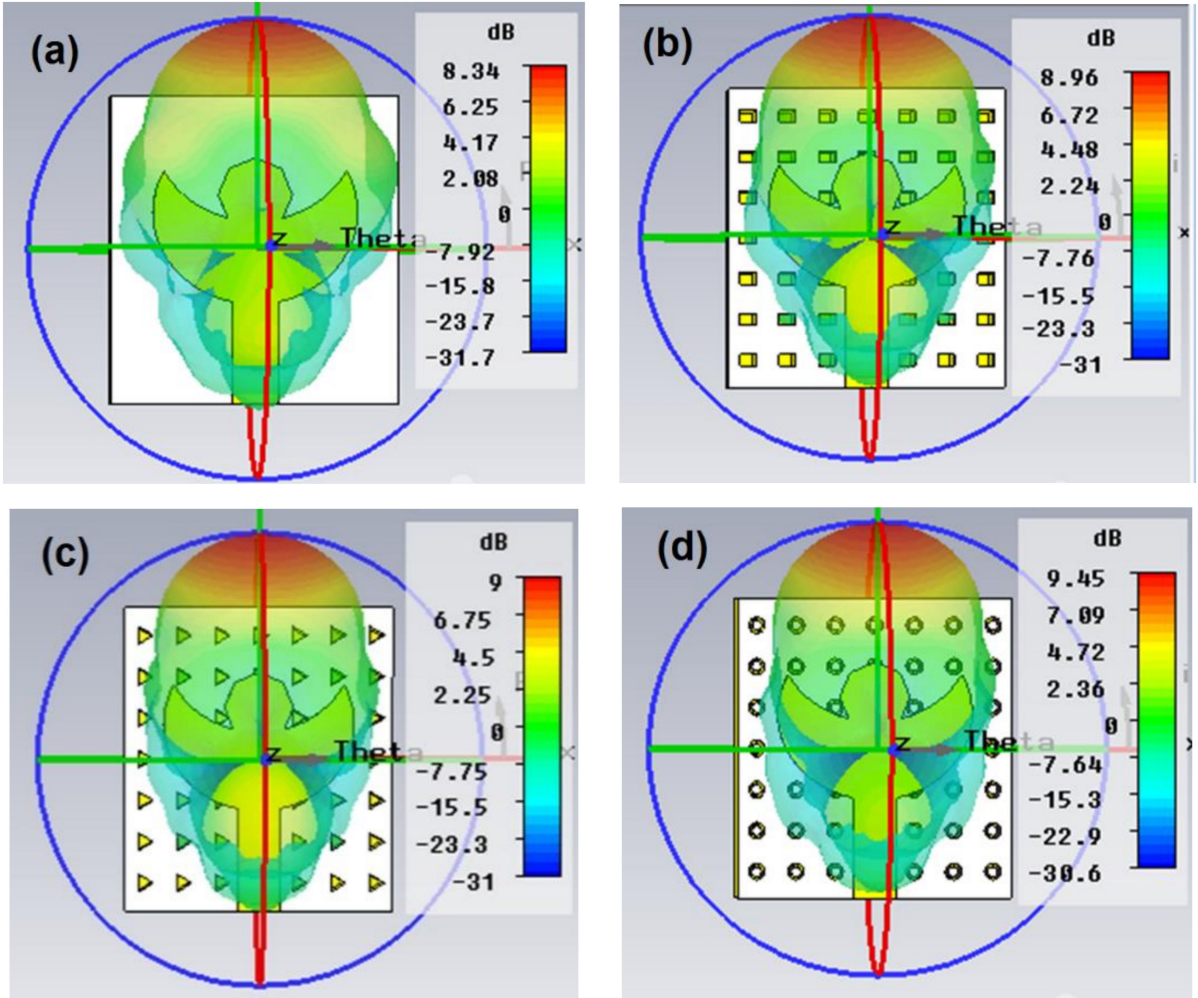

Figure 10. Three-dimensional gain plots of the design antennas (a) Type-A antenna (b) Type-B antenna (c) Type-C antenna (d) Type-D antenna.
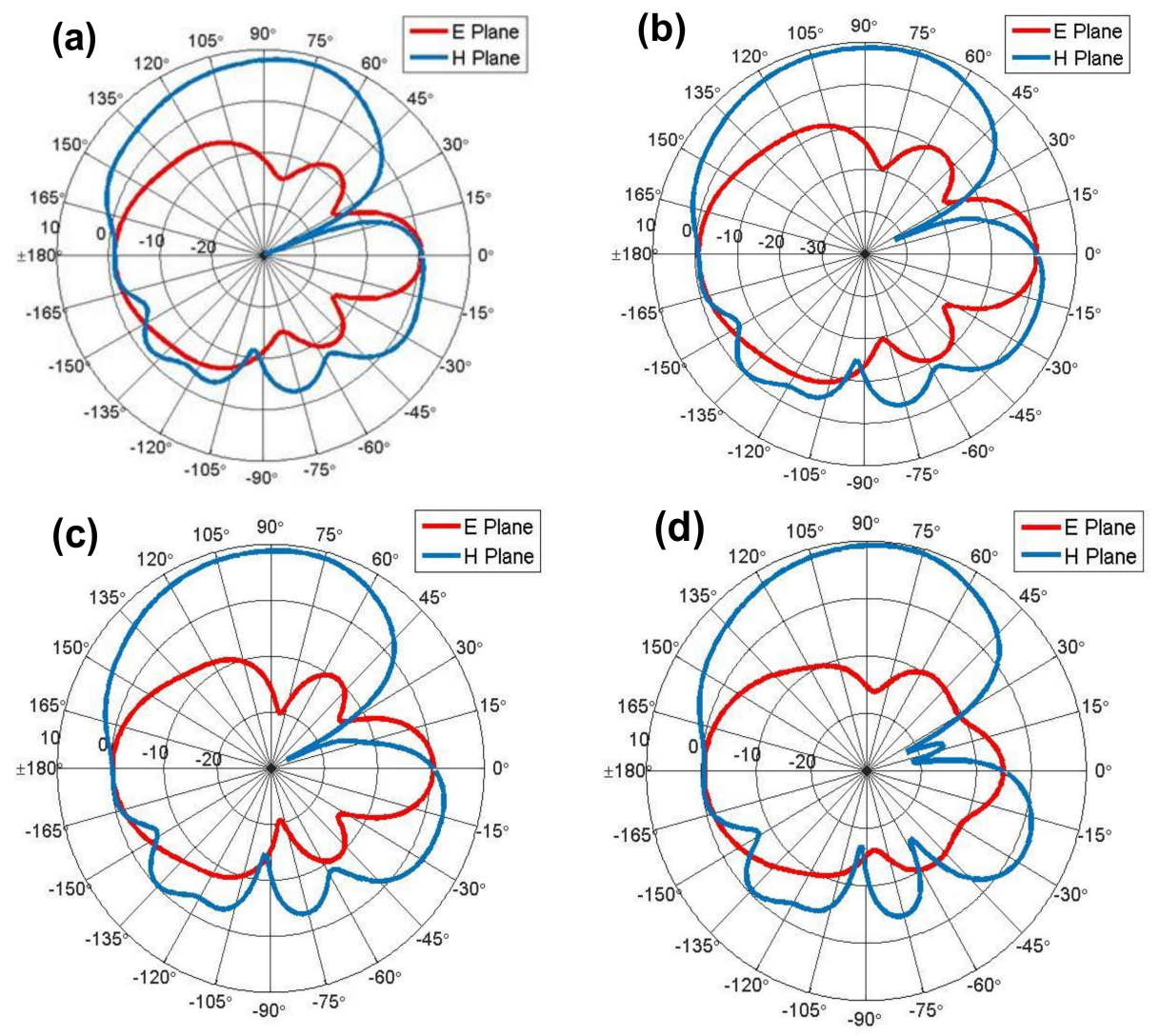

Figure 11. Two-dimensional gain plots of the design antennas (a) Type-A antenna (b) Type-B antenna (c) Type-C antenna (d) Type-D antenna. 
In Figure $12 \mathrm{a}, \mathrm{b}$, the electric field distribution of Type-A and Type-D antennas at a frequency of $0.63 \mathrm{THz}$ is presented. It is observed that the electric field intensity at the upper and lower edges of the proposed modules was more intense than in the central region.

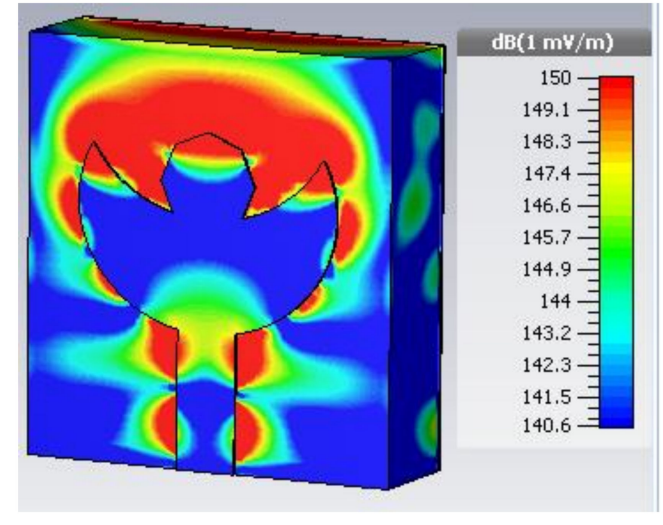

(a)

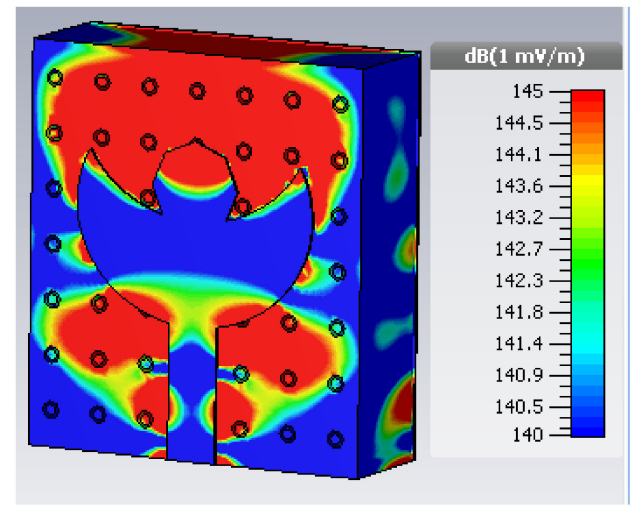

(b)

Figure 12. Electric Field distribution at $0.63 \mathrm{THz}(\mathbf{a})$ Type-A antenna (b) Type-D antenna.

\section{Parametric Analysis}

Based on the analysis in the previous section, it is evident that the Type-D antenna gives better radiation characteristics at $0.63 \mathrm{THz}$ as compared to other candidate antennas. The effect of varying the hole radius $(r)$ of the PBG unit cell on the return loss and gain of the proposed Type-D antenna was investigated. An increase in the radius of the hole resulted in a proportional increase in the resonant frequency as shown in Figure 13a. It can be observed that radii of $16 \mu \mathrm{m}$ provided the optimum value of return loss $(-60 \mathrm{~dB})$ at $0.63 \mathrm{THz}$. For a radius of $28 \mu \mathrm{m}$, the resonant frequency was shifted to $0.66 \mathrm{THz}$ with a larger value of return loss $(-28 \mathrm{~dB})$. The gain variation with change in radii is shown in Figure $13 b$, which verifies that the highest value of peak gain $(9.45 \mathrm{~dB})$ was achieved at $0.63 \mathrm{THz}$ if the radius was set equal to $16 \mu \mathrm{m}$. A proportional drop in gain was observed if the radius was increased above this value. The performance metrics of the $\mathrm{THz}$ antennas presented in this manuscript are compared in Table 3 with other antennas proposed in the recent literature [23-27]. The comparison shows that the proposed antenna gives improved results in terms of gain, directivity, bandwidth, and radiation efficiency. It can be observed in the comparison that the performance of the Type-D antenna among the proposed designs is better in terms of gain, VSWR, directivity, and return loss at the resonance frequency of $0.63 \mathrm{THz}$. As polyamide-based antennas are more affected by the humidity as compared to FR4 or RT/Duroid material, the relative permittivity of the substrate increases with the absorption of water. The amount of absorption depends on the temperature and moisture level, as well as the structural design of the substrate. The compactness and hole-based design of the proposed antenna makes it suitable to be used in humid conditions, similar to the recently proposed breathable antennas [28]. Fabrication and testing of $\mathrm{THz}$ antennas at such high frequency range requires high-cost facilities which were not available to the authors at the time of publication. In addition to the cost, fabrication of a highly efficient coupling port (between the source and the antenna) and the required ultra-high precision for thin substrates is still an issue, even with the use of special procedures such as the batch processing mechanism [29]. Fabrication constraints for $\mathrm{THz}$ antennas need to be considered during the design process. The compactness of the device and requirement of special fabrication environment makes it costly and challenging as this process consists of substrate preparation, antenna pattering over the substrate, and testing. Recent developments in electron-beam lithography allows sub-micron dimensions for such devices, but for feeding mechanism, waveguide-fed or probe-fed with a probe station, a highly efficient coupling port (between the source and the antenna) is still a difficult task to achieve. In addition, antenna gap geometry is another challenging factor, which is the 
space where the electron-hole pairs are generated and coupled to the antenna electrodes, making the fabrication accuracy very important to avoid electric short circuit.

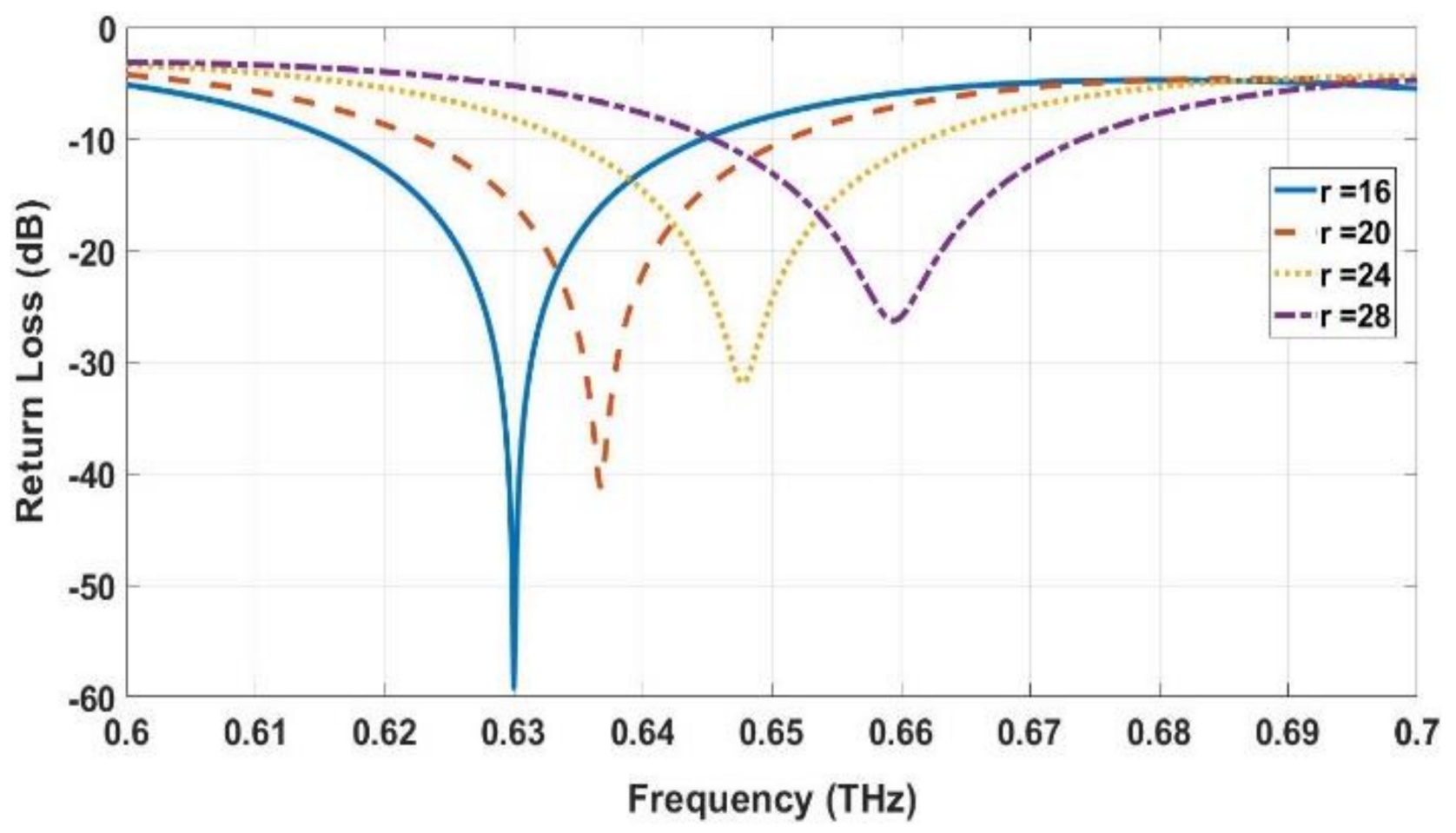

(a)

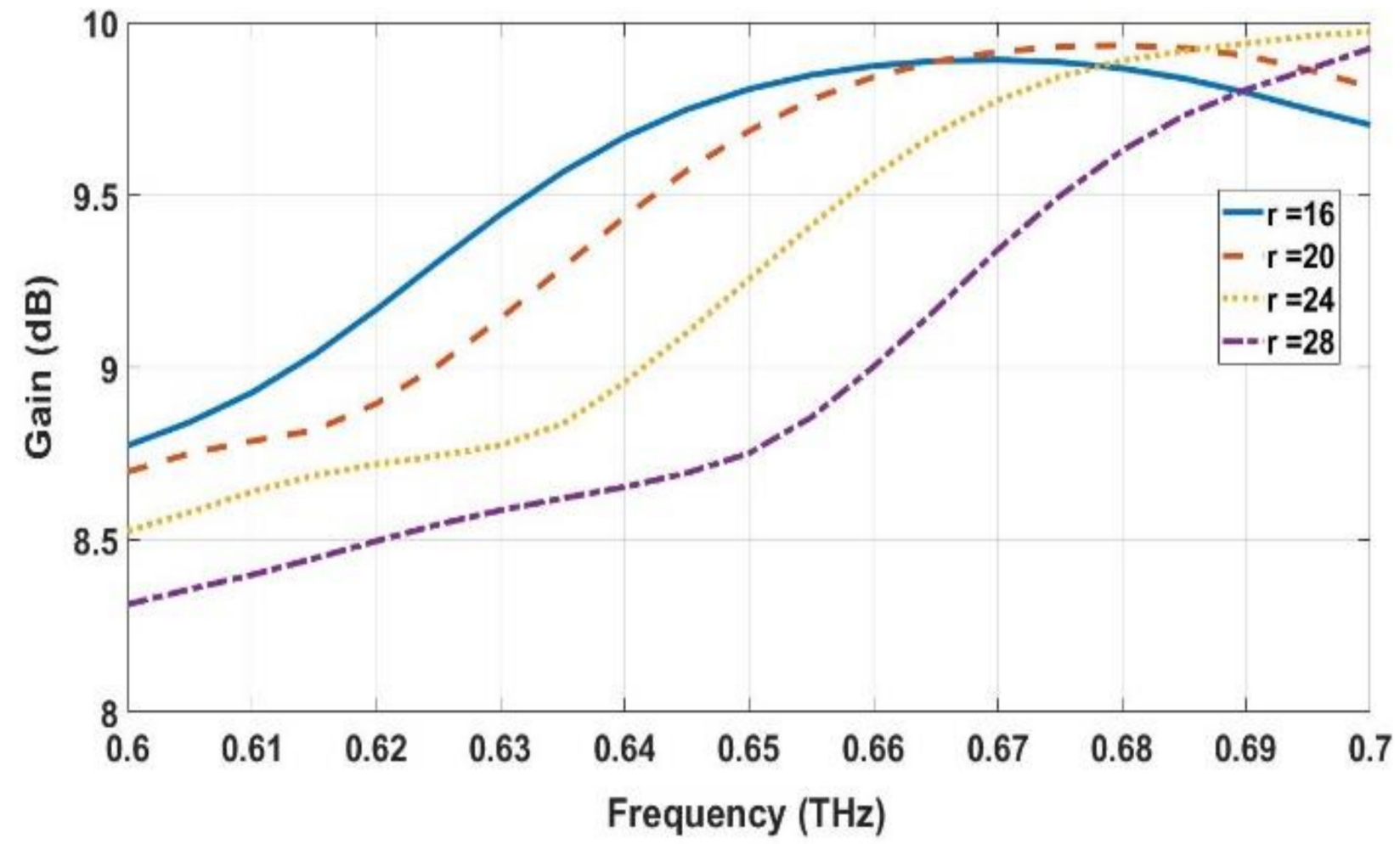

(b)

Figure 13. Parametric analysis of the proposed antenna by varying the radius, $r$ of the PBG unit cell (a) return loss comparison (b) gain comparison. 
Table 3. Comparison of the proposed antenna with sate of the art work.

\begin{tabular}{|c|c|c|c|c|c|c|c|}
\hline Particular & $\mathrm{f}_{\mathrm{r}}(\mathrm{THz})$ & $S_{11}(\mathrm{~dB})$ & BW (GHz) & Gain (dB) & Directivity (dBi) & VSWR & Rad: Efficiency \\
\hline [23] & 1.04 & -17.59 & $* * *$ & 7.99 & 8.24 & $* * *$ & 91.1 \\
\hline [24] & 0.96 & -15.70 & $* * *$ & $* * *$ & $* * *$ & 1.39 & $* * *$ \\
\hline [25] & 0.690 & -34.9 & 24 & 6.88 & 7.01 & 1.043 & $* * *$ \\
\hline [26] & 0.703 & -50.94 & 26.4 & 5.24 & 6.81 & 1.005 & $* * *$ \\
\hline [27] & 0.6308 & -44.71 & 36.23 & 7.94 & 8.61 & 1.012 & 85.7 \\
\hline This work (Type-A) & 0.63 & -28.49 & 28.88 & 8.34 & 8.9 & 1.02 & 82.6 \\
\hline This work (Type-B) & 0.633 & -53.11 & 26.47 & 8.96 & 9.48 & 1.07 & 88.6 \\
\hline This work (Type-C) & 0.626 & -47.79 & 27.84 & 9 & 9.5 & 1.04 & 89.5 \\
\hline This work (Type-D) & 0.63 & -59.15 & 29.79 & 9.45 & 10.1 & 1.0001 & 90.6 \\
\hline
\end{tabular}

$* * *=$ Not Given.

\section{Conclusions}

In this paper, multiple variants of a planar $\mathrm{THz}$ antenna operating at $0.63 \mathrm{THz}$ were designed using different types of PBG-based substrates. For comparison purposes, a similar antenna with a homogeneous polyimide substrate was used. It was observed that better gain $(>9.4 \mathrm{~dB})$, directivity $(>10 \mathrm{~dB})$, and impedance bandwidth $(>29 \mathrm{GHz})$ were achieved by the proposed antenna with Type-D, which is backed by the circular-shaped unit cell PBG substrate. The effects of varying the radii of the circular insertions on the return loss and gain of the antenna were investigated. The $\mathrm{THz}$ antennas reported in this work are compared with other reported $\mathrm{THz}$ antennas and results show the improvement in terms of gain and bandwidth. Thus, the antenna can be a prospective candidate for modern $\mathrm{THz}$ applications, such as spectroscopy, sensing, medical diagnosis, and high data rate wireless hotspots.

Author Contributions: Conceptualization, I.A., S.U. (Sadiq Ullah) and S.U. (Shakir Ullah); Formal analysis, I.A.; Funding acquisition, A.G., M.A., S.K. and E.L.; Methodology, U.H., I.A., S.U. (Shakir Ullah), S.U. (Sadiq Ullah), M.A. and A.G.; Project administration, S.U. (Sadiq Ullah) and U.H.; Resources, A.G., S.A., S.K. and A.G.; Software, I.A. and S.U. (Shakir Ullah); Supervision, S.U. (Sadiq Ullah) and U.H.; Validation, S.U. (Sadiq Ullah), I.A., S.U. (Shakir Ullah), M.A. and A.G.; Visualization, E.L., S.K. and M.A.; Writing-original draft, I. A, and S.U. (Shakir Ullah), S.K.; Writing—review and editing, A.G., U.H., S.U. (Shakir Ullah), M.A., S.A. and E.L. All authors have read and agreed to the published version of the manuscript.

Funding: The research was funded by Researchers supporting Project number (RSP-2021/58) of King Saud University, Riyadh. Kingdom of Saudi Arabia.

Data Availability Statement: Data is contained within the article.

Acknowledgments: The authors sincerely appreciate funding from Researchers Supporting Project number (RSP-2021/58), King Saud University, Riyadh, Saudi Arabia.

Conflicts of Interest: The authors declare no conflict of interest.

\section{References}

1. Mei, J.; Zhong, K.; Xu, J.; Xu, D.; Shi, W.; Yao, J. Efficient Terahertz Generation via GaAs Hybrid Ridge Waveguides. IEEE Photon. Technol. Lett. 2019, 31, 1666-1669. [CrossRef]

2. Choi, Y. Performance analysis of multi-gigabit wireless transmission at THz WLAN-type applications. J. Commun. Netw. 2014, 16, 305-310. [CrossRef]

3. Feng, J.; Meng, T.; Lu, Y.; Ren, J.; Zhao, G.; Liu, H.; Yang, J.; Huang, R. Nondestructive Testing of Hollowing Deterioration of the Yungang Grottoes Based on THz-TDS. Electronics 2020, 9, 625. [CrossRef]

4. Federici, J.F.; Schulkin, B.; Huang, F.; Gary, D.; Barat, R.; Oliveira, F.; Zimdars, D. THz imaging and sensing for security applications explosives, weapons and drugs. Semicond. Sci. Technol. 2005, 20, 266-280. [CrossRef]

5. Rong, Z.; Leeson, M.; Higgins, M.; Lu, Y. Nano-Rectenna Powered Body-Centric Nanonetworks. Terahertz Band. Healthc. Technol. Lett. 2018, 5, 113-117. [CrossRef] [PubMed]

6. Beruete, M.; Jáuregui-López, I. Terahertz Sensing Based on Metasurfaces. Adv. Opt. Mater. 2019, 8. [CrossRef] 
7. Ullah, S.; Ahmad, I.; Raheem, Y.; Ullah, S.; Ahmad, T.; Habib, U. Hexagonal shaped CPW Feed based Frequency Reconfigurable Antenna for WLAN and Sub-6 GHz 5G applications. In Proceedings of the 2020 International Conference on Emerging Trends in Smart Technologies (ICETST), Piscataway, NJ, USA, 26 March 2020; pp. 1-4. [CrossRef]

8. Asad, K.M.B.; Girard, J.N.; de Villiers, M.; Ansah-Narh, T.; Iheanetu, K.; Smirnov, O.; Lehmensiek, R.; Jonas, J.; de Villiers, D.I.L.; Thorat, K.; et al. Primary beam effects of radio astronomy antennas-II. Modelling MeerKAT L-band beams. Mon. Not. R. Astron. Soc. 2021, 502, 2970-2983. [CrossRef]

9. Koenig, S.; Lopez-Diaz, D.; Antes, J.; Boes, F.; Henneberger, R.; Leuther, A.; Tessmann, A.; Schmogrow, R.; Hillerkuss, D.; Palmer, R.; et al. Wireless sub-THz communication system with high data rate. Nat. Photon. 2013, 7, 977-981. [CrossRef]

10. Cacciapuoti, A.S.; Sankhe, K.; Caleffi, M.; Chowdhury, K.R. Beyond 5G: THz-Based Medium Access Protocol for Mobile Heterogeneous Networks. IEEE Commun. Mag. 2018, 56, 110-115. [CrossRef]

11. Habib, U.; Aighobahi, A.E.; Quinlan, T.; Walker, S.D.; Gomes, N.J. Demonstration of radio-over-fiber-supported 60 GHz MIMO using separate antenna-pair processing. In Proceedings of the 2017 International Topical Meeting on Microwave Photonics (MWP), Beijing, China, 23-26 October 2017; pp. 1-4. [CrossRef]

12. Temmar, M.N.E.; Hocini, A.; Khedrouche, D.; Zamani, M. Analysis and design of a terahertz microstrip antenna based on a synthesized photonic bandgap substrate using BPSO. J. Comput. Electron. 2019, 18, 231-240. [CrossRef]

13. Roslan, N.H.; Awang, A.H.; Hizan, H.M. The Effect of Photonic Crystal Parameters on The Terahertz Photonic Crystal Cavities Microstrip Antenna Performances. In Proceedings of the 2018 IEEE International RF and Microwave Conference (RFM), Penang, Malaysia, 17-19 December 2018; pp. 147-150. [CrossRef]

14. Choudhury, B.; Danana, B.; Jha, R.M. PBG based terahertz antenna for aerospace applications. In PBG based Terahertz Antenna for Aerospace Applications; Springer: Singapore, 2016; pp. 1-35. ISBN 978-981-287-802-1.

15. Gonzalo, R.; de Maagt, P.; Sorolla, M. Enhanced patch-antenna performance by suppressing surface waves using photonic-band gap substrates. IEEE Trans Microw. Theory Tech. 2016, 47, 2131-2138. [CrossRef]

16. Bala, R.; Marwaha, A. Development of computational model for tunable characteristics of graphene based triangular patch antenna in THz regime. J. Comput. Electron. 2015, 15, 222-227. [CrossRef]

17. Jayasinghe, J.W.; Uduwawala, D.N. A novel miniature multi-frequency broadband patch antenna for WLAN applications. In Proceedings of the 2013 IEEE 8th International Conference on Industrial and Information Systems, Peradeniya, Kandy, 17-20 December 2013; pp. 361-363. [CrossRef]

18. Patel, S.K.; Sonagara, J.; Katrodiya, D.; Sorathiya, V. High gain metamaterial radome design for microstrip based radiating structure. Mater. Res. Express 2018, 6, 025803. [CrossRef]

19. Li, R.; Dejean, G.; Tentzeris, M.; Papapolymerou, J.; Laskar, J. Radiation-pattern improvement of patch antennas on a large-size substrate using a compact soft-surface structure and its realization on LTCC multilayer technology. IEEE Trans. Antennas Propag. 2005, 53, 200-208. [CrossRef]

20. Gupta, S.; Dhillon, S.; Khera, P.; Marwaha, A. Dual band U-slotted microstrip patch antenna for C band and X band radar applications. In Proceedings of the 2013 5th International Conference and Computational Intelligence and Communication Networks, Mathura, India, 27-29 September 2013; pp. 41-45.

21. Balanis, C.A. Antenna Theory: Analysis and Design; John Wiley \& Sons: New York, NY, USA, 2016.

22. CST Microwave Studio CST of America, Inc. Available online: http:/ / www.cst.com (accessed on 12 June 2021).

23. Tripathi, S.K.; Kumar, A. High gain miniaturised photonic band gap terahertz antenna for size-limited applications. Aust. J. Electr. Electron. Eng. 2019, 1-7. [CrossRef]

24. Singh, A.; Singh, S. A trapezoidal microstrip patch antenna on photonic crystal substrate for high speed THz applications. Photon. Nanostructures-Fundam. Appl. 2015, 14, 52-62. [CrossRef]

25. Ullah, S.; Ruan, C.; Haq, T.; Zhang, X. High performance THz patch antenna using photonic band gap and defected ground structure. J. Electromagn. Waves Appl. 2019, 33, 1943-1954. [CrossRef]

26. Paul, L.C.; Islam, M. Proposal of wide bandwidth and very miniaturized having dimension of $\mu \mathrm{m}$ range slotted patch $\mathrm{THz}$ microstrip antenna using PBG substrate and DGS. In Proceedings of the 20th International Conference of Computer and Information Technology (ICCIT), Dhaka, Bangladesh, 22-24 December 2017; pp. 1-6. [CrossRef]

27. Kushwaha, R.K.; Karuppanan, P.; Malviya, L. Design and analysis of novel microstrip patch antenna on photonic crystal in THz. Phys. B Condens. Matter 2018, 545, 107-112. [CrossRef]

28. Memon, A.W.; de Paula, I.L.; Malengier, B.; Vasile, S.; van Torre, P.; van Langenhove, L. Breathable Textile Rectangular Ring Microstrip Patch Antenna at $2.45 \mathrm{GHz}$ for Wearable Applications. Sensors 2021, 21, 1635. [PubMed]

29. Lee, C.; Chattopadhyay, G.; Decrossas, E.; Peralta, A.; Mehdi, I.; Leal-Sevillano, C.A.; Del Pino, M.A.; Llombart, N. Terahertz antenna arrays with silicon micromachined-based microlens antenna and corrugated horns. In Proceedings of the IEEE 2015 International Workshop on Antenna Technology (iWAT), Seoul, Korea, 4-6 March 2015; pp. 70-73. [CrossRef] 